\title{
EFFECT OF UNMODIFIED COW'S MILK INTAKE DURING THE FIRST 20 MONTHS OF LIFE ON INFANTS' AND TODDLERS' MORBIDITY
}

\author{
S. Nyankovskyy, O. Ivakhnenko, D. Dobryanskyy \\ Department of Paediatrics, L'viv National Medical University, L'viv, Ukraine
}

An optimal age at which unmodified caw's milk could be introduced into the baby's diet remains contradictory. The aim of the study was to estimate the possible negative influence of unmodified caw's milk (UCM) intake on morbidity and incidence of food hypersensitivity reactions during the first 20 months of life.

Methods: Retrospective evaluation of morbidity, incidences of food hypersensitivity reactions was done in a cohort of 1000 babies who were divided into 3 groups depending on their nutrition. 135 babies did not receive UCM for the 20 months (the first group). 471 received UCM during the first year of life (the second group). 394 babies were fed with UCM starting from the second year of life (the third group). Medical record reviews were performed and special questionnaire was used.

Results: Babies from the first group had lower incidence of food hypersensitivity reactions $(17,04 \%$ vs. $49,26 \%$ and $51,52 \%$ in the $2^{\text {nd }}$ and $3^{\text {rd }}$ groups accordingly; $\left.p<0,001\right)$. The incidences of diarrhoea $(4,48 \%$ vs. $17,2 \%$ and $13,23 \%$ accordingly; $p=0,014)$, pneumonia $(0,11 \pm 0,39$ vs. $0,26 \pm 0,6$ and $0,22 \pm 0,7$ episodes; $\mathrm{p}=0,046)$, average number of hospitalizations $(0,25 \pm 0,64$ vs. $0,56 \pm 1,0$ and $0,46 \pm 0,79 ; \mathrm{p}=0,0035)$ and antibiotics administration $(0,57 \pm 0,99$ vs. $1,23 \pm 1,5$ and $1,22 \pm 1,21$ courses; $p=0,0001)$ were also different in the groups.

Conclusions: Introduction of UCM into baby's diet during the first 2 years of life may lead to increased hypersensitivity reaction incidence, infectious morbidity, numbers of hospitalization and courses of antibiotics administration. 